\title{
Um Estudo da Parábola: Quadros, Registros de Representação Semiótica e Pontos de Vista
}

\author{
A Study of the Parable: Frames, Records of Semiotic Representation and Points \\ of View
}

\author{
Carlos Alberto Fernandes de Siqueira ${ }^{*}$ \\ Pontifícia Universidade Católica de São Paulo - PUCSP \\ Maria José Ferreira da Silva** \\ Pontifícia Universidade Católica de São Paulo - PUCSP
}

\begin{abstract}
Resumo
Neste artigo faremos um estudo bibliográfico com a finalidade de fazer uma reflexão a respeito do estudo da parábola a partir das noções de Quadros, Pontos de Vista e de Registros de Representação Semiótica. Não temos a intenção de esgotar o assunto, pois estamos interessados apenas no que se refere ao ensino básico. Assim, articulamos no quadro da Geometria os pontos de vista do corte entre plano e cone, e de lugar geométrico utilizando o registro material, o registro figural e o registro algébrico. A partir desse estudo mudamos o ponto de vista para o quadro da Geometria Analítica representando a parábola no plano cartesiano, que a caracteriza agora como um registro gráfico e o articulamos com o obtido como representação algébrica no quadro anterior para desenvolver outras representações algébricas, as equações.
\end{abstract}

Palavras-Chave: Parábola, Quadros, Registros, Pontos de Vista.

\begin{abstract}
In this article we will make a bibliographical study with the purpose of making a reflection about the study of the parable from the notions of frame, Points of View and Register of Semiotic Representation. We do not intend to exhaust the matter because we are only interested in basic education. Thus, we articulate in the framework of Geometry the points of view between the plane and the cone, and of the geometric location using the material register, the figural register and the algebraic register. From this study we change the point of view to the framework of Analytical Geometry representing the parable in the cartesian plane, which now characterizes it as a graphic record and articulate it with that obtained as algebraic representation in the previous frame to develop other algebraic representations, the equations.
\end{abstract}

Keywords: Parable, Frames, Registers, Points of View.

\footnotetext{
* Doutorando em Educação Matemática pela Pontifícia Universidade Católica de São Paulo (PUCSP). São Paulo, São Paulo, Brasil. E-mail: calbertofisica@yahoo.com.br.

** Doutora em Educação Matemática pela Pontifícia Universidade Católica de São Paulo (PUCSP). Professora Assistente Doutor da Graduação, do Programa de Estudos Pós Graduados em Educação Matemática e da Especialização em Educação Matemática da Pontifícia Universidade Católica de São Paulo. São Paulo, São Paulo, Brasil. E-mail: zeze@pucsp.br.
} 


\section{Introdução}

De acordo com Siqueira (2016) a parábola é a cônica mais estudada no ensino básico a partir do nono ano do ensino fundamental e primeiro ano do ensino médio, com base no estudo de função quadrática por meio de diferentes formas de representações, gráficas, algébricas e tabular. No terceiro ano do ensino médio essa curva é estudada com foco na geometria analítica, principalmente, a partir da definição de lugar geométrico em que a parábola faz parte do estudo das cônicas e desvinculada do objeto função.

Bordallo (2011) revelou que no terceiro ano do ensino médio as cônicas são frequentemente introduzidas por meio do corte entre o plano e o cone circular reto de duas folhas e que a parábola é uma curva proveniente desta interseção quando o plano é posicionado paralelamente à reta geratriz do cone. No entanto, para a autora, este é um recurso ilustrativo de um recorte histórico apenas para justificar o nome cônicas e estuda-las, em seguida, no quadro da geometria analítica.

De acordo com Siqueira (2016) essa maneira de introduzir o estudo das cônicas é um ponto de vista para o ensino, pouco explorado e, quando utilizado, aparece de forma desarticulada com o ponto de vista de lugar geométrico no quadro da geometria, estudado aqui pela definição focal.

Por outro lado, o autor afirma que nas Orientações Curriculares para o Ensino Médio (BRASIL, 2006) a parábola é considerada um conteúdo complementar cabendo ao professor avaliar a pertinência de seu ensino ou não, considerando o projeto político-pedagógico da escola. Caso queira ensinar, sugerem estudar esta curva como lugar geométrico de pontos acompanhado de sua equação canônica, ou seja, escolhendo bem a posição da representação da parábola em um sistema de coordenadas cartesianas, focando um estudo para este objeto na geometria analítica.

Já no currículo do Estado de São Paulo (SÃO PAULO, 2011) o ensino da parábola está previsto para o terceiro ano do ensino médio, no quadro da geometria analítica, sendo tratada por meio de equações canônicas cujas representações gráficas têm vértice na origem dos sistemas de coordenadas cartesianas. No entanto as pesquisas consultadas por Siqueira (2016) apontaram para a necessidade de estudar a parábola também no quadro da geometria, em particular, segundo o ponto de vista de lugar geométrico. Neste sentido, o autor entendeu a relevância do estudo da parábola nesse quadro como um meio de preparar o estudante para seu estudo em geometria analítica. 
Assim, no que segue apresentaremos um breve aporte teórico no sentido de esclarecer o que entendemos por Quadro, Ponto de Vista e Registro de Representação semiótica para em seguida, articulá-los em um estudo a respeito de parábola.

\section{Aporte Teórico}

A importância do estudo que pretendemos realizar a respeito de parábola em função das noções de quadros, registros e pontos de vista é defendido por Douady (1994, p. 11, tradução nossa) quando afirma que:

As interconexões entre quadros diferentes ou as mudanças de ponto de vista ou de registro no interior de um quadro, realizados para avançar em um problema, são meios pelos quais se manifesta a flexibilidade do pensamento. Eles oferecem ocasiões para confrontar ideias, pesquisar coerências, controlar resultados. Entretanto, implementar tais procedimentos não ocorrem por si. Requer uma verdadeira educação.

Assim, neste trabalho utilizaremos a definição de quadro baseado em Douady e PerrinGlorian (1989, p. 389) que o entende "constituído de objetos de um ramo da matemática, de relações entre os objetos, de suas formulações eventualmente diferentes e de imagens mentais que o sujeito associa, em um dado momento, à esses objetos e essas relações”. (Tradução nossa).

Para obter formulações diferentes para um problema, a autora apresenta a noção de mudança de quadros, pois esta permite um novo acesso às dificuldades encontradas e a possibilidade de utilização de ferramentas e técnicas que não eram possíveis na primeira formulação. Acrescenta que essa interação entre quadros faz progredir os conhecimentos em cada um deles. Já a noção de jogo de quadros são as "mudanças de quadros provocadas por iniciativa do professor" a fim de que os alunos sejam capazes de realizar tais mudanças quando possíveis para resolver os problemas que lhes são propostos.

Para Rogalski (2001, p. 14-15) afirma que:

a grosso modo, dizemos que trabalhamos em um determinado quadro se estudamos um problema em que os dados, os enunciados, as primeiras ferramentas de estudo, se situam em uma teoria principal muito bem definida, mais ou menos vasta, que tem relação com um campo conceitual no sentido de Vergnaud. Um quadro aparece assim como um domínio de trabalho [...] trata-se sobretudo de marcos, uteis para analisar os problemas, para classificar, para descrever relações para situar objetos matemáticos precisos, então uteis também para pesquisar e para ensinar e em particular para prever as mudanças de quadro.

De acordo com Duval (2009) para ter um status de registro de representação semiótica um sistema de representação semiótica deve permitir três atividades cognitivas fundamentais ligadas à semiosis: a formação de representações, o tratamento e a conversão. A formação tem 
o papel de "constituir um traço ou um ajuntamento de traços perceptíveis que sejam identificáveis como uma representação de alguma coisa em um sistema determinado" (p.36). O tratamento implica em "transformar as representações apenas por regras próprias ao sistema, de modo a obter outras representações que possam constituir uma relação de conhecimento em comparação às representações iniciais” (p. 36-37).

Uma conversão, por sua vez, permite "converter as representações produzidas em um sistema em representações de um outro sistema, de tal maneira que estas últimas permitam explicar outras significações relativas ao que é representado. (p. 37).

Para Duval (2009) a atividade matemática requer a utilização de registros de representação semiótica, indispensáveis tanto para a comunicação, quanto para o desenvolvimento da própria atividade. Assim, a coordenação de vários registros é necessária para a compreensão conceitual.

A respeito de registros Rogalski (2001, p.15) afirma que “os registros são modos de representação de objetos matemáticos, acompanhados de regras de tratamentos, que permitem estudar os problemas." Acrescenta que as regras de conversão não são precisas, pois nem sempre conduzem todas as propriedades acessíveis no registro inicial para o registro de chegada e, também não conservam de maneira isomorfa as regras de tratamento. Para o autor, nem sempre é fácil distinguir entre quadros e registros porque alguns registros são mais adaptados a certos quadros.

Segundo Rogalski (2001, p.17) a noção de ponto de vista trata:

de uma noção sem dúvida menos precisa que as de quadro e de registro. Já, podemos dizer que mudar de quadro ou mudar de registro para estudar um objeto matemática, é uma mudança de ponto de vista sobre esse objeto. Mas, podemos também mudar produtivamente de ponto de vista permanecendo em um mesmo quadro ou um mesmo registro.

A esse respeito, Artigue (1994, p.15), tratando do ponto de vista do ambiente informático, afirma que

a articulação de estruturas e registros, como toda articulação de pontos de vista, é uma operação mental cognitivamente muito dispendiosa e não é por acaso que o ensino tende, com frequência, a evitar essa complexidade compartimentando os assuntos e as abordagens. As articulações se constroem lentamente e essa construção envolve, como bem mostram as pesquisas recentes, toda uma rede cognitiva que ultrapassa amplamente as simples articulações visadas.

Por outro lado, para Rogalki (2001, p. 26) preferências pessoais podem estimular a mudança de quadros de registro ou de pontos de vista e, frequentemente, os alunos se sentem mais confortáveis utilizando certos quadros ou registros que outros. Afirma ainda que estas preferencias pessoais devem ser consideradas no ensino a partir da constatação de que o 
trabalho em um só quadro ou um só registro não favorece a aprendizagem.

Assim, o professor deve considerar o jogo de quadros em suas intervenções de modo que os alunos sejam capazes de identificar as mudanças de quadros necessárias e, resolver os problemas que lhes são propostos. Neste sentido, para Almouloud (2007, p. 81)

Pontos de vista diferentes, para um objeto matemático, são maneiras diferentes de olhálo, e de fazê-lo funcionar, e eventualmente, de defini-lo. Neste sentido, olhar um objeto em diferentes quadros é ter diferentes pontos de vista, embora se possam ter vários pontos de vista no mesmo quadro.

Portanto, dado um problema em um determinado quadro podemos mudar de ponto de vista, mudando para um outro quadro para resolvê-lo ou no mesmo quadro mudar de ponto de vista ou de registro. A partir deste referencial teórico construímos um estudo para a parábola que apresentamos no que segue.

\section{Um Estudo Da Parábola - Articulação Entre Quadro, Registro E Ponto De Vista}

Neste estudo apresentamos o objeto matemático parábola nos quadros da geometria e da geometria analítica, buscando diferentes pontos de vista para estudá-la, além de diferentes maneiras de representá-la. Justificamos a escolha desses dois quadros porque focaremos em conteúdos trabalhados no ensino básico, embora a parábola seja objeto de estudo em outros quadros como geometria projetiva, geometria não euclidiana, entre outros.

\subsection{Quadro Da Geometria}

No quadro da geometria de acordo com Siqueira (2016) a parábola pode ser estudada a partir de diferentes representações por meio do ponto de vista do corte entre plano e cone, pelo ponto de vista de lugar geométrico e pelo ponto de vista da excentricidade.

Pelo ponto de vista do corte entre plano e cone de duas folhas (figura 1) podemos perceber que se o plano de corte intercepta o cone paralelamente a uma de suas geratrizes, obtemos na intersecção o formato de uma parábola. Esta percepção, no entanto, não nos fornece qualquer propriedade a respeito dessa curva, o que torna necessário uma mudança de ponto de vista. 


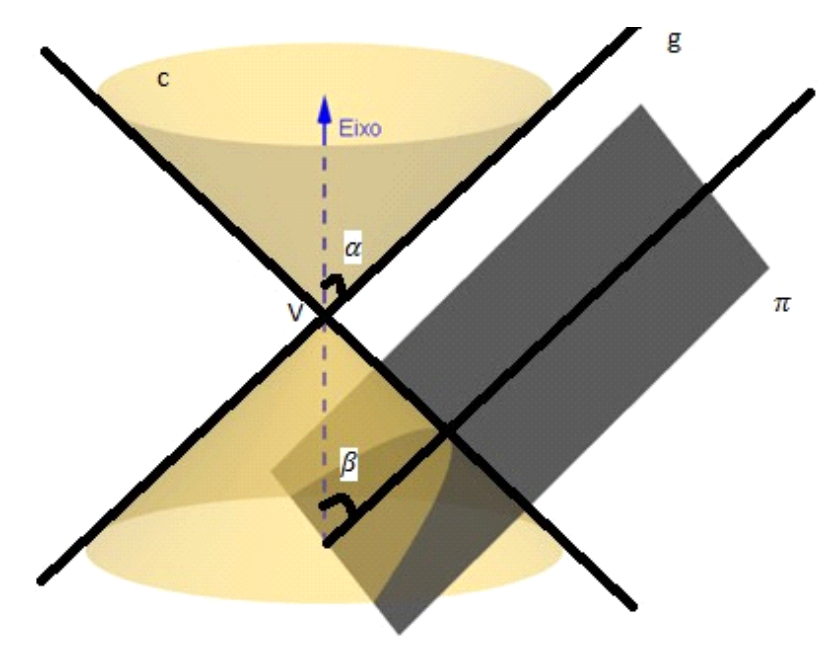

Figura 1: Interseção entre pano e cone de duas folhas Fonte: Siqueira (2016, p.72)

O ponto de vista do corte de um cone por um plano já era conhecido de Menaecmus, que viveu por volta de 360 a.C. e que definiu as três cônicas a partir de um cone circular reto para a parábola, um cone circular agudo para a elipse e um cone circular obtuso para a hipérbole, bem como várias propriedades para essas curvas. De acordo com Boyer (2010) as secções cônicas já eram conhecidas há pelos menos um século e meio quando Apolônio, no século III a.C., escreveu sua obra As cônicas, em que mostra que as três cônicas podem ser obtidas a partir de um único cone.

De acordo com Siqueira (2016) esse ponto de vista é introduzido de forma isolada no ensino da parábola no quadro da geometria, carecendo de articulações para um melhor entendimento deste conteúdo.

No entanto, um questionamento possível a respeito desse ponto de vista seria como realizar as representações dessas curvas em um plano. O que é necessário para tal?

De acordo com Zavala e Rodriguez (2012) Meneacmus possuía um dispositivo para construir cônicas, assim como Mileto que teria um instrumento para traçar parábolas dentre outros. Mas, de acordo com Delefrate e Saito (2017) apesar de algumas tentativas terem sido realizadas para representar as cônicas no plano, como o caso de Mydorge que as traçava por marcação de pontos, foi Schooten no século XVII que partindo dos tratamentos dados às cônicas, tanto por Euclides, quanto por Apolônio, propõe "traçar as cônicas por um movimento contínuo, por meio do uso de instrumentos [...] para construir essas figuras no plano". (p.97). Seu interesse estava voltado para construção de lentes, relógios de sol, entre outros, ou seja, questões práticas.

Podemos então utilizar esses dois métodos, por pontos ou por uso de instrumentos, como possíveis de conduzir os alunos à percepção da propriedade da parábola que identifica cada 
ponto pertencente a ela como sendo equidistante de uma reta e de um ponto fixo. Entendemos que esses métodos conduzem ao ponto de vista de lugar geométrico em que essa propriedade pode ser observada por meio de diferentes representações. Considerando um registro material como definido por Jesus (2008) podemos, a partir de uma folha de papel vegetal determinar tantos pontos quanto possíveis para determinar a representação de uma parábola. Como mostra a figura (2) a partir do traçado de uma reta $r$ e de um ponto $F$ fora dela podemos dobrar o papel de modo a sobrepor os pontos da reta com o ponto $F$.

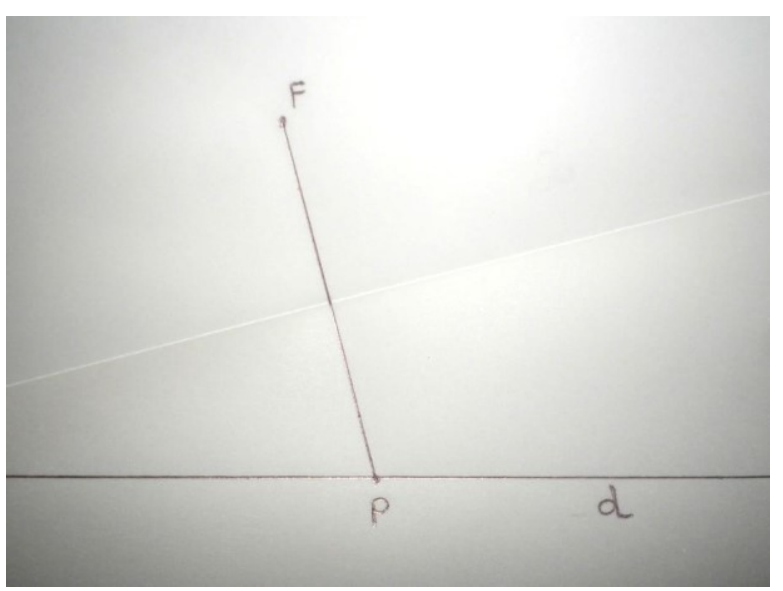

Figura 2: Esboço da primeira reta obtida na dobra do papel Fonte: Lopes (2014, p. 56)

Depois de certo número de dobras, tratamentos no sentido de Duval, a percepção de uma curva vai se formando como mostra a figura 3.

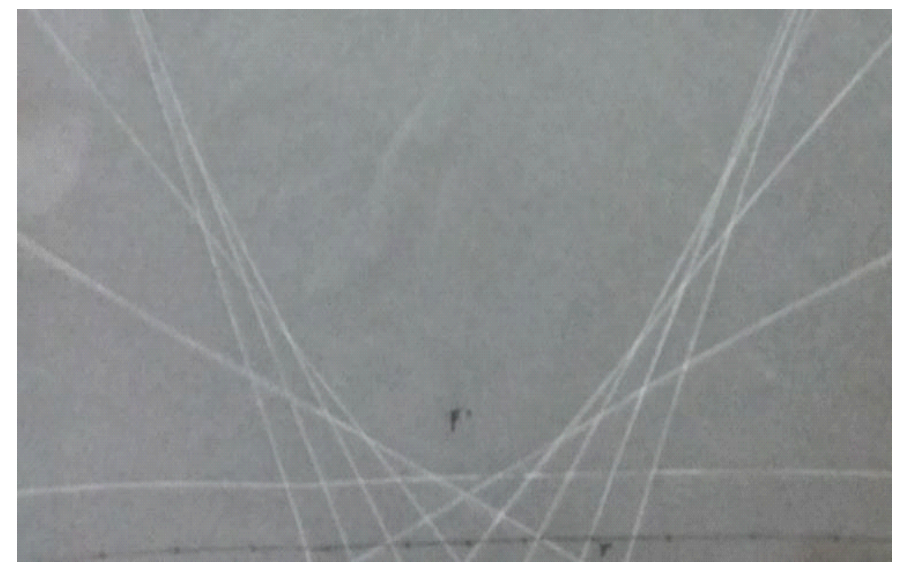

Figura 3: Registro material da Parábola

Fonte: Siqueira (2016, p. 73)

Na construção dessa representação de parábola por meio de dobradura podemos apenas, em um primeiro momento, perceber qual é a cônica desenhada, contudo é possível desenvolver um discurso que justifique tais construções. As dobras no papel representam as mediatrizes de segmentos com extremidades nos pontos tomados sobre a reta $r$ e no ponto $F$ e, portanto, a 
medida da distância de cada ponto da parábola à reta e ao ponto $F$ é a mesma.

Essa constatação pode ser verificada de uma outra forma, a partir da construção da representação de uma parábola pelo método do fio esticado ou método de Kepler que permitirá desenvolver um discurso associado à figura geométrica. Essa técnica de construção implica no traçado de uma reta e de um ponto fora dela em uma folha de papel e depois amarrar uma extremidade de um barbante, de comprimento qualquer, em um prego fixado no ponto $F$ e a outra no vértice de $30^{\circ}$ de um esquadro que deverá estar apoiado em uma régua (marcando a reta). Como mostra a figura 4, o lápis esticará o barbante apoiando-se no esquadro e este irá deslizar para a direita e para a esquerda descrevendo uma parábola. Como o barbante tem a mesma medida fixa teremos a representação de uma parábola, pois a ponta do lápis está a uma mesma distância tanto do ponto (foco) quanto da reta diretriz (régua).

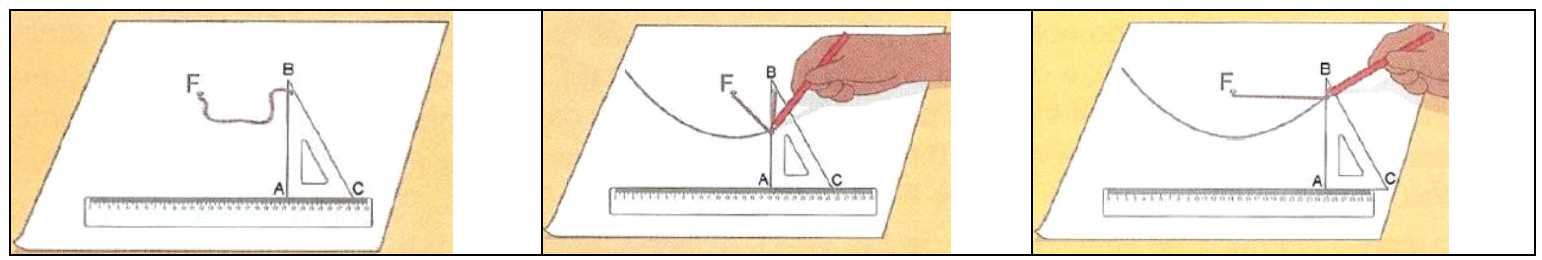

Figura 4: Parábola pelo método do fio esticado

Fonte: Sousa (2010, p. 216)

Podemos também construir a figura geométrica de uma parábola, no registro figural, a partir de pontos, utilizando ferramentas do desenho geométrico como régua e compasso, que permitirá verificar a propriedade da simetria na representação de uma parábola. Para essa construção utilizamos régua e compasso e algumas técnicas de desenho geométrico. A partir da construção de uma reta $d$ e um ponto $F$ fora dela, traçamos uma reta $r$ perpendicular à reta $d$ que passa por $F$ e intercepta a reta d em um ponto $M$ (ver figura 5).

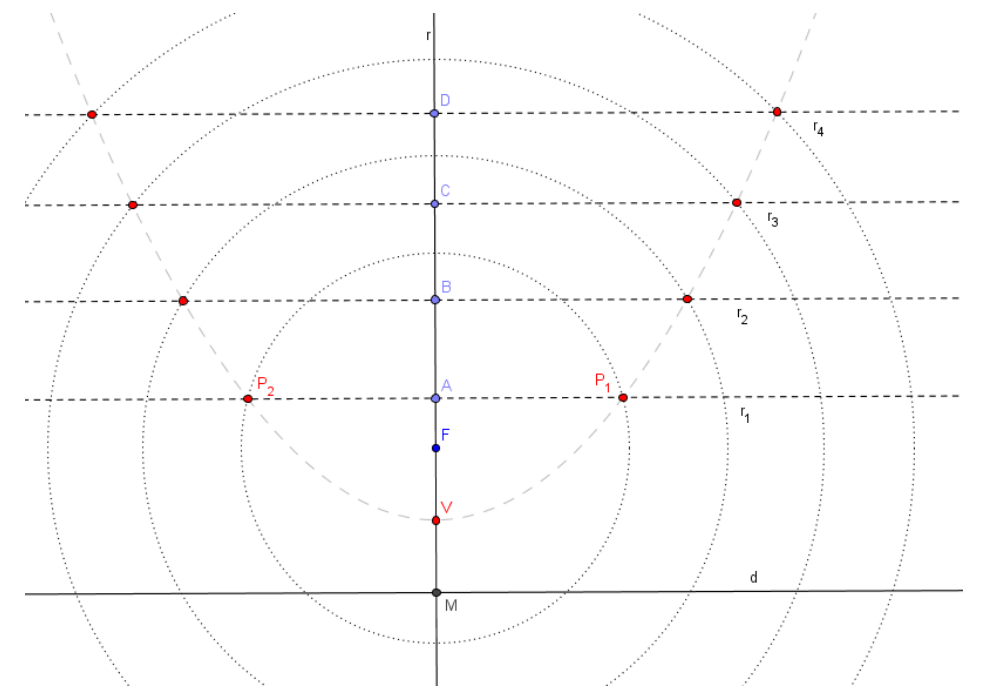

Figura 5: Parábola construída por régua e compasso Fonte: Produção dos autores 
Determinamos então o ponto $V$, médio entre os pontos $F$ e $M$, que chamaremos de vértice da representação figural da parábola. A partir daí escolhemos outros pontos sobre a reta $r, A, B, C, D, \ldots$ para traçar, por eles, outras retas, $r_{1}, r_{2}, r_{3}, \ldots$ perpendiculares à reta $r$. Com um compasso traçamos uma circunferência com centro em $F$ e raio de medida igual $M A$ que intercepta a reta $r_{1}$ em dois pontos, $P_{1}$ e $P_{2}$, que pertencem à parábola, pois $M A$ é igual a distância do ponto da parábola até a reta $d$ e igual à distância do ponto $F$ à esse mesmo ponto. Repetimos esse processo para traçar outras circunferências e com isso conseguir representar o maior número de pontos que pertencem à essa parábola. Cabe ressaltar que existem outros processos de construção da representação de uma parábola por pontos que não trataremos neste artigo.

Assim, a parábola pode ser definida como o lugar geométrico dos pontos do plano que equidistam de uma reta dada e de um ponto fora dela e nomear esses elementos como sendo, respectivamente, a reta diretriz e o foco da parábola. A condição de lugar geométrico e a propriedade da equidistância, que um ponto $P$, qualquer da figura de uma parábola está a igual distância do foco $F$ e da reta diretriz $d$, nos permite a realização de outra conversão de registros, agora para o registro algébrico quando escrevemos $d(P, F)=d(P, d)$.

Até o momento as representações apresentadas possuem natureza estática, pois foram construídas em uma folha de papel, no entanto tão importante quanto elas, é a representação dinâmica, pois esta pode ser movimentada e propiciar tanto o levantamento de conjecturas. Com as conclusões obtidas nas construções anteriores podemos então fazer uma conversão para o registro figural dinâmico e com a ajuda da ferramenta rastro do software de representação dinâmica Geogebra (figura 3) produzir representações para a parábola semelhantes às produzidas por dobradura de papel.

Para produzir essa representação determinamos a reta diretriz $d$ e o foco $F$ fora dela. Em seguida, determinamos um ponto qualquer $G$ sobre a reta $d$ e por ele traçamos uma reta perpendicular à reta $d$. O ponto $P$ (figura 6) que pertencerá a representação da parábola é a intersecção da reta perpendicular à diretriz com a mediatriz do segmento $F G$. 


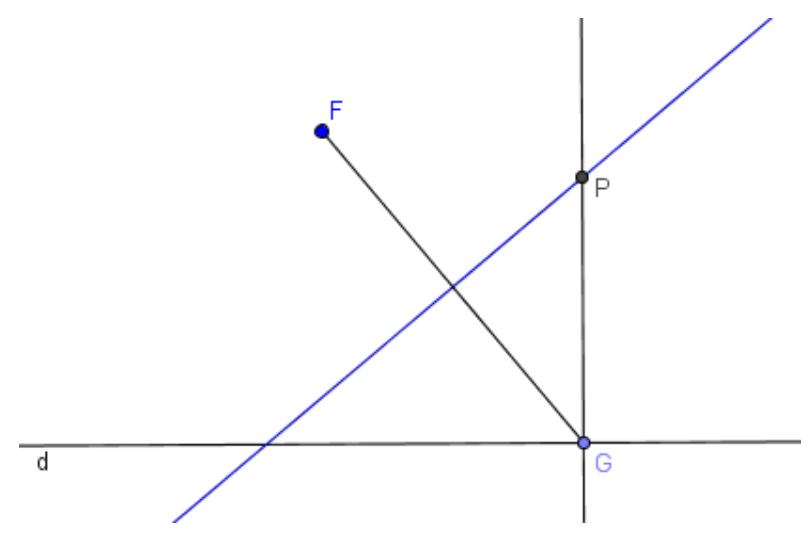

Figura 6: Representação de um ponto da parábola por mediatriz Fonte: produção dos autores

Utilizando a ferramenta rastro, habilitada para a mediatriz do segmento $F G$ movimentamos o ponto $G$ sobre a reta diretriz para obter outras retas (figura 7) como as obtidas nas dobras do papel.

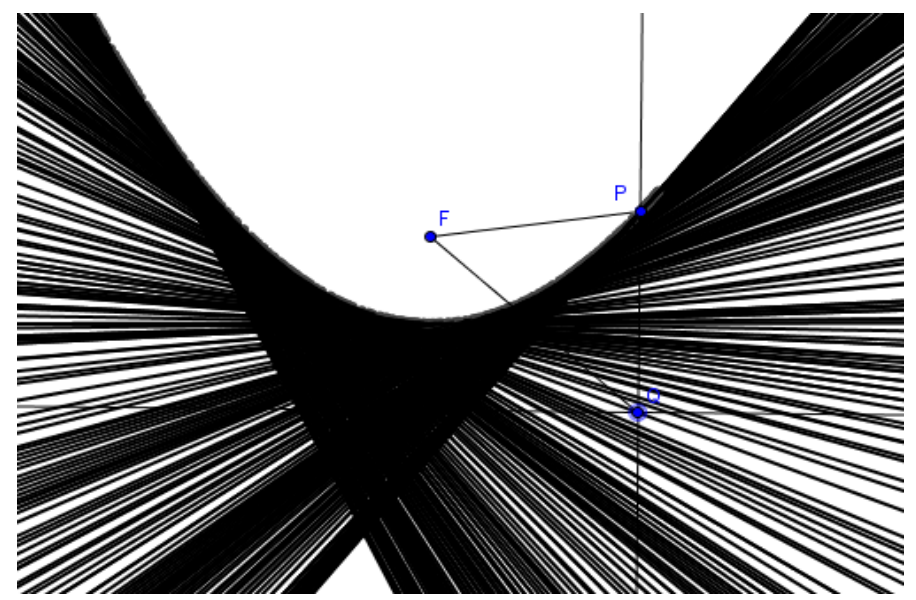

Figura 7: Representação de uma parábola pela ferramenta rastro do Geogebra - mediatriz Fonte: Siqueira (2016, p. 60)

Ainda com a ferramenta rastro do Geogebra podemos reproduzir a construção por pontos da figura 5 e utilizá-lo a partir da construção da primeira circunferência. Determinados os pontos $P_{1}$ e $P_{2}$ (figura 8) habilitamos o rastro para eles e movimentamos o ponto A sobre a reta $r$ e assim, obter a representação figural de uma parábola. 


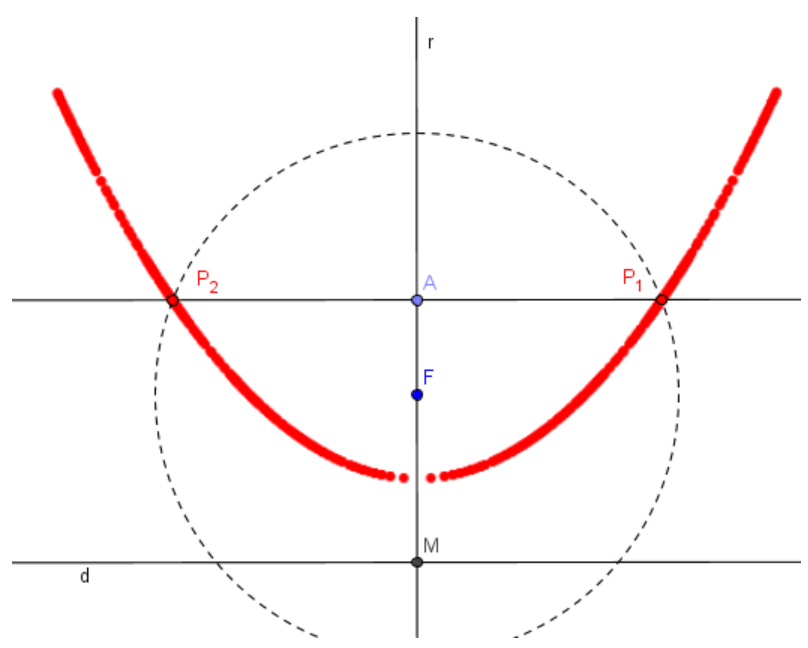

Figura 8: Representação de uma parábola pela ferramenta rastro do Geogebra - pontos Fonte: produção dos autores

Podemos ainda, a partir da definição de parábola como lugar geométrico e da ferramenta própria do Geogebra, construir uma representação figural de uma parábola como mostra a figura 9. O procedimento é idêntico ao realizado para obter a figura 6, porém habilitamos a ferramenta lugar geométrico e selecionamos os pontos $G$ e $P$, ou seja, queremos determinar o lugar geométrico do ponto $P$ quando o ponto $G$ percorre a reta $d$.

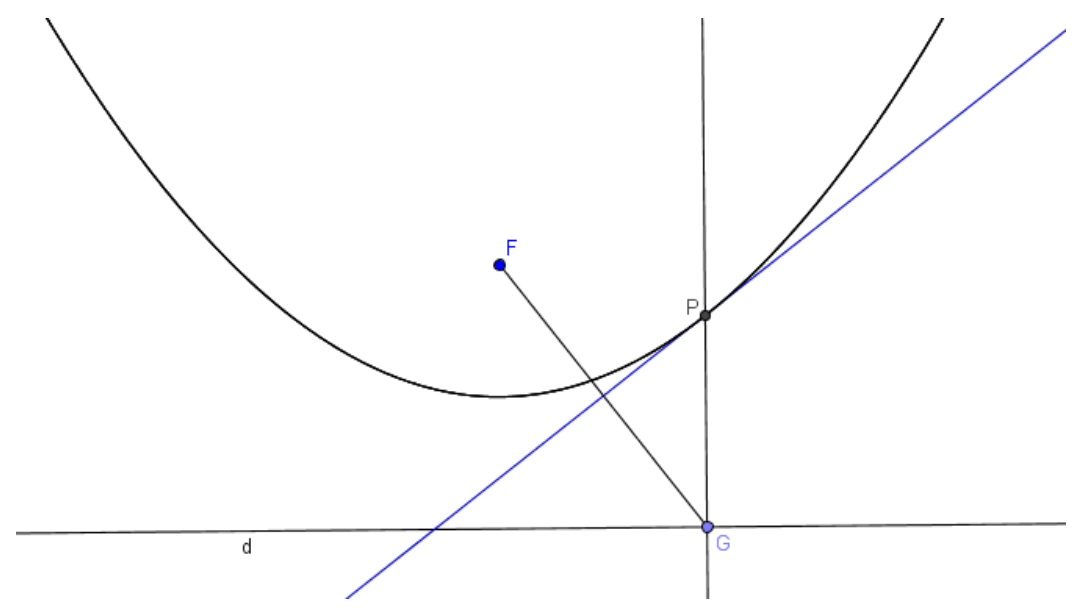

Figura 9: Representação de uma parábola por lugar geométrico no Geogebra Fonte: Produção dos autores

Para dar um exemplo de como as noções de quadros, registros e pontos de vista se intercruzam e se relacionam percebemos que no quadro da geometria e no registro figural a parábola pode ser estudada de outra maneira ainda no ponto de vista de lugar geométrico, como apresentado por Almouloud, Koné e Sangaré (2014) quando consideraram a propriedade de tangência à circunferência. Nesse caso, a parábola é definida como o conjunto dos pontos de um plano que representam os centros de circunferências que tangenciam uma reta dada e passam por um ponto fora dessa reta (figura 10). 


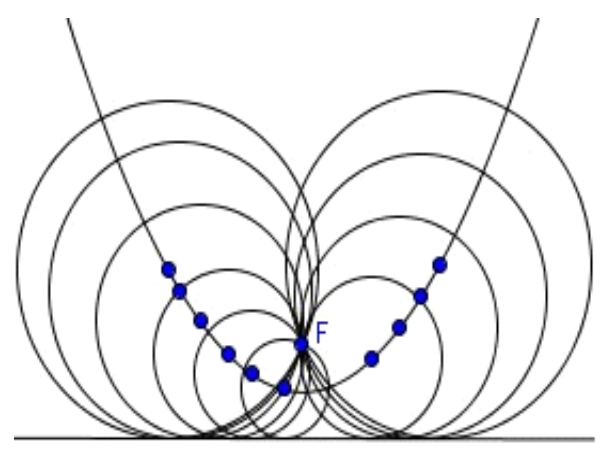

d

Figura 10: Parábola construída pelo método das circunferências Fonte: Siqueira (2016, p. 94)

Por essa definição a distância entre um ponto qualquer da parábola ao foco e à reta diretriz é representada pela medida do raio da circunferência. Tal construção se justifica quando consideramos a figura 11 e nela observamos que dado uma reta $\mathrm{r}$ e um ponto $F$ fora dela, um ponto $Q$ qualquer de $r$ é ponto de tangência de uma circunferência com centro em $F$. Assim, o lugar geométrico dos pontos equidistantes do ponto $F$ e da reta $r$ é representado pelos centros das circunferências que passam por $F$ e tangenciam a reta $r$ e descreve a representação de uma parábola. Neste sentido, se $P$ é o centro da circunferência de medida de raio $n$ então $P F=$ $P Q=n$. Há outras maneiras de construir uma parábola por lugar geométrico que não trataremos aqui.

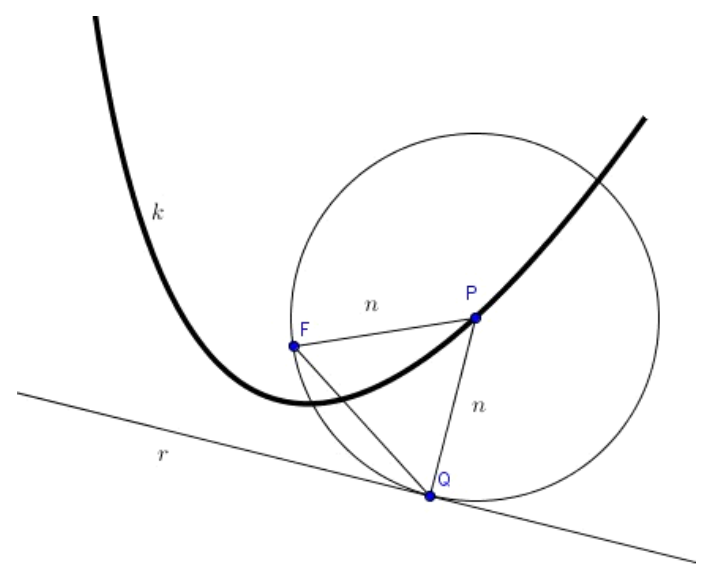

Figura 11: Registro de base para verificação da equidistância no método das circunferências Fonte; Siqueira (2016, p. 95)

Percebemos que um estudo inicial para construção de representações e de definições para a parábola, no quadro da geometria sem, neste momento, se preocupar com suas diversas propriedades requer um trabalho com materiais manipulativos, com o uso de softwares e a realização de conversões de registros de representação, material, figural, algébrico. Requer também a mudança de pontos de vista, do corte entre plano e cone e do ponto de vista de lugar 
geométrico, este podendo ocorrer de maneiras diferentes.

A partir das possíveis maneiras de representar uma parábola no registro figural observamos que podemos definir a parábola de maneiras diferentes embora equivalentes, como afirma Siqueira (2016). O autor utiliza o teorema de Dandelin para mostrar a equivalência entre o ponto de vista do corte do cone por um plano e o ponto de vista de lugar geométrico. Segundo o autor Dandelin considerou uma esfera inserida em um cone de modo a tangenciar simultaneamente o plano de corte e o cone, como mostra a figura 12 e enunciou o seguinte teorema: A secção de uma superfície cônica de revolução por um plano oblíquo ao eixo é uma parábola, uma elipse ou uma hipérbole.

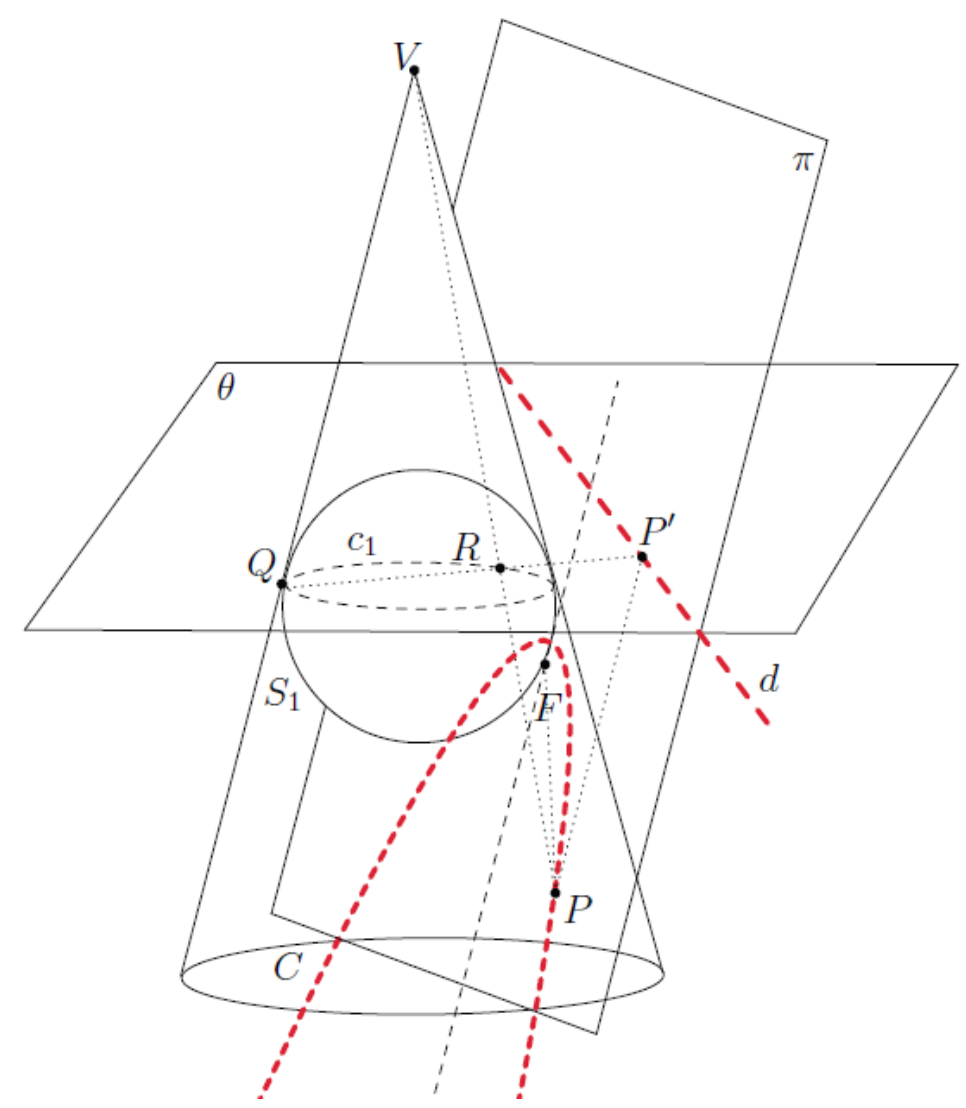

Figura 12: Base para a demonstração do Teorema de Dandelin (Parábola) Fonte: Monteiro (2014, p.14)

Considerando um cone $C$ de vértice $V$, a esfera $S_{l}$, o plano $\pi$ que corta esse cone e um plano $\theta$ paralelo à base do cone. Tomamos o ponto $F$, de interseção entre o plano $\pi$ e a esfera; a reta $d$, interseção entre o plano $\pi$ e o plano $\theta$; o círculo $c_{1}$, contido no plano $\theta$ e obtido pela interseção entre o cone $C$ e a esfera $S_{1}$; o ponto $Q$ de tangencia entre uma geratriz do cone e o circulo $c_{1}$. Além desses elementos consideramos $P$, um ponto qualquer na representação da parábola, $R$ um ponto que pertence a $c_{1}$ e à geratriz que contém $P$, e $P^{\prime}$ a projeção ortogonal de $P$ sobre a reta $d$. De posse desses elementos temos que mostrar que $P F=P P^{\prime}$. Por meio da 
propriedade de tangência às esferas verificamos a congruência dos segmentos $V Q$ e $V R$ e dos segmentos $P R$ e $P F$ que nos conduz a concluir que os triângulos isósceles $V Q R$ e $R P P^{\prime}$ são isósceles e que, portanto, $P P^{\prime}=P F$.

Desta forma partimos do ponto de vista do corte do cone por um plano e mostramos que a parábola é o lugar geométrico dos pontos que equidistam de uma reta e de um ponto dado. Tal verificação permite então promover articulações entre eles.

O trabalho até aqui apresentado permite a mobilização da representação figural de uma parábola para o plano cartesiano e então estuda-la no quadro da geometria analítica.

\subsection{Quadro Da Geometria Analítica}

De acordo com Eves (2004) o início do desenvolvimento da Geometria Analítica é creditado a Descartes e a Fermat. Neste quadro colocamos em correspondência curvas no plano e equações de duas variáveis na medida em que transportamos elementos importantes de uma parábola para um referencial cartesiano.

Realizando uma mudança do quadro da geometria para o quadro da geometria analítica podemos estudar a parábola representada no registro gráfico e no registro gráfico, mobilizando a definição desse objeto enquanto lugar geométrico. Essa mudança caracteriza também uma mudança de ponto de vista, pois permite uma outra maneira de "ver" a parábola, além de disponibilizar outros recursos para solucionar problemas que a envolvem. Com os recursos já disponíveis podemos representa-la como mostra a figura 13.

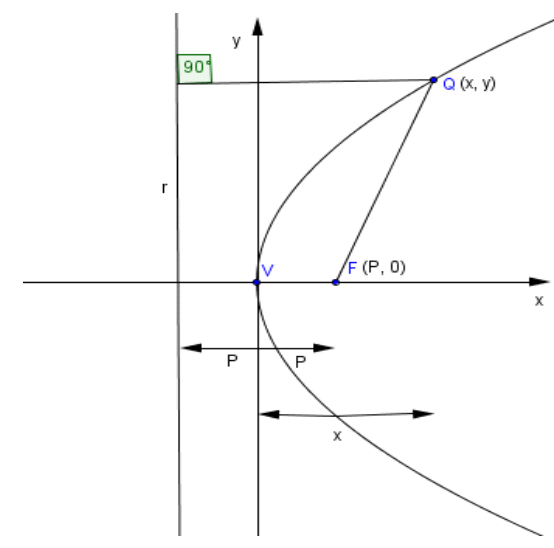

Figura 13: Registro gráfico de uma Parábola Fonte: Siqueira (2016, p. 119)

A partir dos elementos da figura 13, podemos considerar, por exemplo, a reta $\mathrm{r}$ de equação $x=-p$, como a reta diretriz; um ponto $Q$, fora dela e ainda a relação $d(Q, r)=$ $d(Q, F)$, da definição de lugar geométrico caracterizando uma conversão do registro figural 
para o registro gráfico. Como essa conversão permite a representação de pontos por pares ordenados, podemos fazer uma conversão do registro gráfico para o registro algébrico de modo a encontrar equações para esta cônica.

Dessa forma, se considerarmos $p$ a distância entre o foco, $F(p, 0)$, e o vértice da parábola, sabemos que a medida entre o foco e a reta diretriz é $2 p$. Considerando $Q(x, y)$, um ponto qualquer pertencente à parábola e a relação $d(Q, r)=d(Q, F)$, podemos escrever que $|x+p|=\sqrt{(x-p)^{2}+y^{2}}$. A partir de tratamentos algébricos podemos chegar à equação equivalente: $x^{2}+2 p x+p^{2}=x^{2}-2 p x+p^{2}+y^{2}$ que, por tratamentos de simplificação, pode ser representada por $y^{2}=4 p x$, uma nova representação no registro algébrico para a parábola.

Outras equações reduzidas podem ser deduzidas de representações gráficas diferentes, figura 14, de acordo com a posição da reta diretriz, $x=p, y=p$ ou $y=-p$ e do mesmo tratamento algébrico apresentado anteriormente, ou seja, respectivamente, $y^{2}=-4 p x, x^{2}=$ $4 p y$ e $x^{2}=-4 p y$.

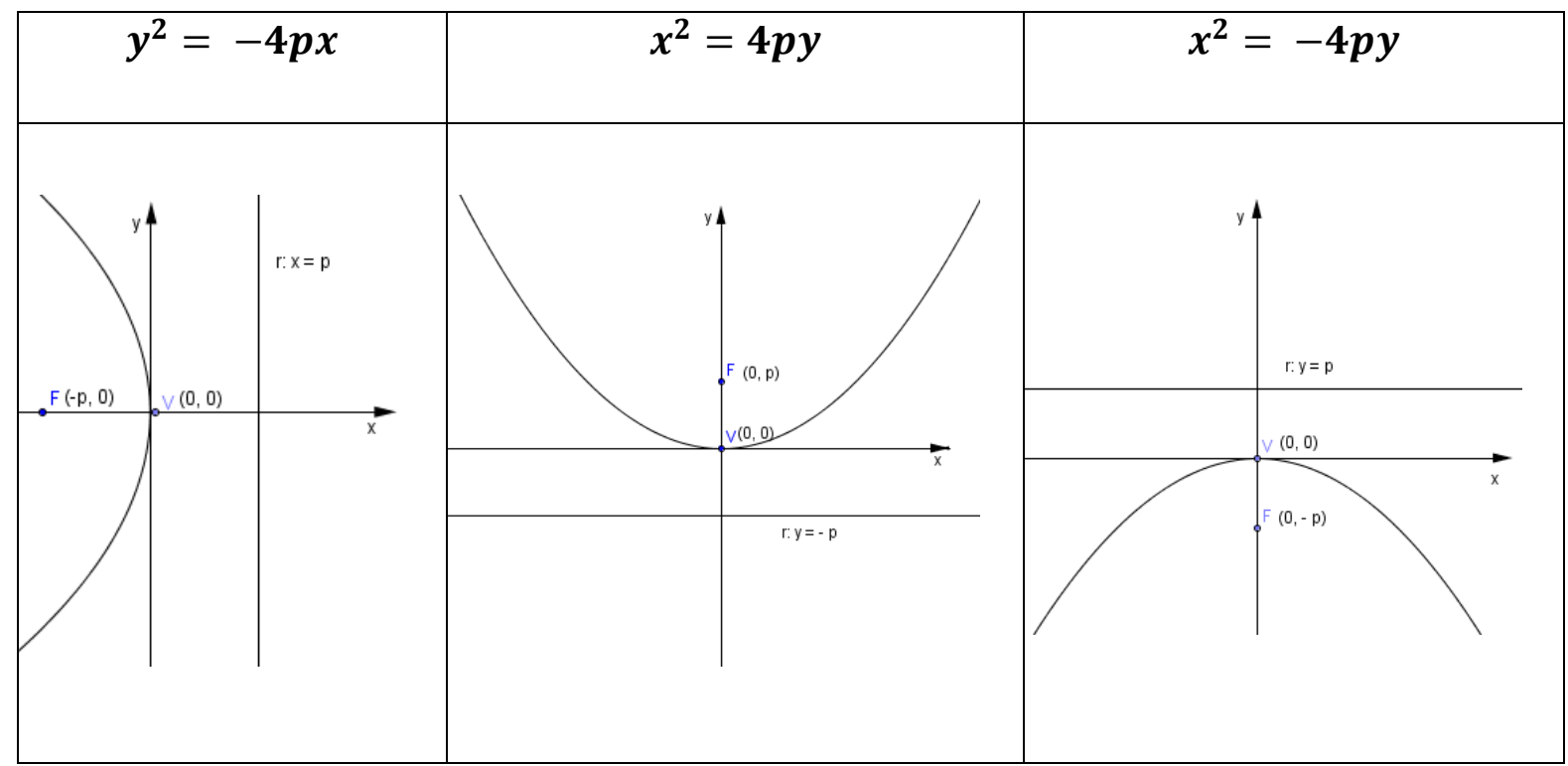

Figura 14: Diferentes gráficos para a Parábola

Fonte: Siqueira (2016, p. 120)

No quadro da geometria analítica pelo ponto de vista analítico podemos ter outros recursos para a solução de problemas e a constatação de propriedades para a parábola.

\section{Considerações Finais}

A parábola, enquanto um objeto matemático, pode ser estudada no quadro da geometria desde recursos como instrumentos de desenho, barbantes, papel ou softwares de modo a 
conduzir o aluno a perceber e validar algumas propriedades que a definem. Esse enfoque conduz à produção de maneiras de representar diferentes para essa curva, ou seja, em um registro material, registro figural ou registro figural dinâmico. A construção dessas representações conduz à definição da parábola enquanto um lugar geométrico: a parábola é o conjunto dos pontos do plano que equidistam de uma reta dada e de um ponto dado, que muitos autores se referem como sendo a definição geométrica para parábola. No entanto a parábola, enquanto lugar geométrico, pode ser obtida por outras relações, entre elas que: a parábola é o conjunto de pontos que representam os centros das circunferências que passam por um ponto fixo e tangenciam uma reta dada.

No entanto, muitos trabalhos mostram que o ensino privilegia o ensino da parábola via corte de um cone por um plano, sem justificar sua relação com a definição geométrica por lugar geométrico. O teorema de Dandelin que apresenta uma equivalência matemática entre os dois pontos de vista, não é estudado e arriscamos afirmar que é desconhecido por muitos professores. De figuras que mostram a relação do corte de um cone por um plano com as cônicas ou de construções mecânicas para elas, o ensino propõe seu ensino prioritariamente no quadro da geometria analítica.

A parábola, em particular, é vista pelos alunos, geralmente, no nono ano do ensino fundamental como uma representação de função quadrática o que é reforçado nos anos iniciais do ensino médio com a continuidade do estudo dessa função. Passará a ser um objeto matemático, independente de uma função, apenas no final desse nível de ensino, quando tratada, em geometria analítica.

Entendemos que antes da introdução de funções os alunos devam ter contato com a parábola no quadro da geometria para que possam identificar essa curva como provável representação de uma função, quando este for o assunto de estudo. Porém, o que ocorre, em geral, é a caracterização da parábola apenas no quadro funcional, sua representação geométrica no registro figural, isto é, sem referencial cartesiano é identificada como representação de uma função quadrática. Assim, acreditamos que para uma efetiva aprendizagem do que é uma parábola e da possiblidade de sua utilização como representação de função ela deva ser tratada no quadro da geometria antes do quadro da geometria analítica. Algumas ideias para isso foram aqui apresentadas. 


\section{Referências}

ALMOULOUD, Saddo Ag. (2007). Fundamentos da didática da matemática. Curitiba: UFPR.

ALMOULOUD, S. A., KONÉ, C, \& SANGARÉ, M. S (2014). Study of the mathematical and didactic organizations of the conics in the curriculum of secondary schools in the republic of Mali. RIPEM, v. 4, (3). Recuperado de https://www.researchgate.net/publication/275648839 STUDY OF THE MATHEMATI CAL AND DIDACTIC ORGANIZATIONS OF THE CONICS IN THE CURRICU LUM OF SECONDARY SCHOOLS IN THE REPUBLIC OF MALI

ARTIGUE, M. (1994). Ferramenta informática. Ensino de Matemática formação de professores. In: Em Aberto, Brasília, ano 14, (62), p.9-22.

BORDALLO, M. (2011). As Cônicas na matemática escolar brasileira: história, presente e futuro (Dissertação de Mestrado em Ensino de Matemática) - Universidade Federal do Rio de Janeiro. Rio de Janeiro.

BOYER, Carl B. (2010). História da Matemática. $3^{\mathrm{a}}$ Ed. Tradução: Elza F. Gomide. São Paulo: Blucher.

BRASIL. (2006). Secretaria da Educação básica. Orientações curriculares para o ensino médio: Ciências da natureza, matemática e suas tecnologias. v.2. Brasília.

DELEFRATE, E. H., \& SAITO, F. (2017). Alguns breves apontamentos sobre o tratado de organica conicarum sectionum in plano descriptione de Frans van Schooten. Revista de Produção Discente. Educação Matemática. Recuperado de: https://revistas.pucsp.br/pdemat/article/view/35423/24250

DOUADY, R. (1994). Ingénierie didactique et évolution du rapport au savoir. IREM. Recuperado http://www.cndp.fr/entrepot/fileadmin/docs/education_prioritaire/Maths et ZEP/reperes1 5rd.pdf

DOUADY, R., \& GLORIAN, M. J. P. (1989). Un processus d'apprentissage du concept d'aire de surface plane. Educational Studies in Mathematics. Recuperado de: https://link.springer.com/article/10.1007/BF00315608

DUVAL, Raymond. (2010). Semiósis e Pensamento Humano. São Paulo: Livraria da Física.

EVES, Howard. (2004). Introdução à história da matemática. Tradução: Domingues, Higyno H. Campinas: Unicamp.

JESUS, G. B. (2008). Construções geométricas: uma alternativa para desenvolver conhecimentos acerca da demonstração em uma formação continuada (Dissertação de Mestrado em Educação Matemática). Pontifícia Universidade Católica de São Paulo, São Paulo.

MONTEIRO, R. M. (2014). Resgate do Teorema de Dandelin no Estudo de Cônicas com o 
Geogebra. (Dissertação de Mestrado em Matemática). Universidade Federal do Espírito Santo, Vitória.

ROGALSKI, M. (2001, junho). Les chagements de cadre dans La pratique dês mathématiquas et le jeu de cadre de Règine Douady. In: Actes de La jounée em hommage à Règine Douady, Université Paris. Recuperado de: http://numerisation.univirem.fr/PS/IPS02004/IPS02004.pdf

SÃO PAULO. (2011). Secretaria da Educação. Currículo do Estado de São Paulo: Matemática e suas tecnologias. São Paulo.

SIQUEIRA, C. A. F. (2016). Um Estudo Didático das Cônicas: Quadros, Registros e Pontos de Vista. Dissertação (Dissertação de Mestrado em Educação Matemática). Pontifícia Universidade Católica de São Paulo, São Paulo.

ZAVALA, J. C. C., \& RODRÍGUEZ, H. A. S. (2012). Uso de artefactos concretos en actividades de geometría analítica: una experiencia com la elipse. REDIMAT. Recuperado de: http://hipatiapress.com/hpjournals/index.php/redimat/article/view/211/pdf

Submetido em: 06/05/2018

Aceito em: 12/09/2019 